\title{
IMPROVEMENT OF IQ-3 PROCESSES TO ELIMINATE CRACK FORMATION, DECREASE DISTORTION, AND MAXIMIZE MATERIAL STRENGTH, AND DUCTILITY
}

\author{
Nikolai Kobasko \\ Intensive Technologies Ltd \\ 68/1 Peremohy ave., Kyiv, Ukraine, 03113 \\ nkobasko@gmail.com
}

\begin{abstract}
The paper presents an overview and significant improvement of one of the intensive quenching processes (namely, the IQ-3 process). The IQ-3 process is an interrupted quench method that is usually implemented in high-velocity single-part quenching IQ units. The IQ-3 process is often called a direct convection quenching since, due to a very high water flow rates through the quench chamber, both the film boiling process and the nucleate boiling process are eliminated completely, and convention process starts immediately after beginning of the quench. Different criteria of the IQ-3 process interruption are considered. Normally, the IQ-3 process is interrupted at a time when current surface compressive stresses are at their maximum value. After a conventional IQ-3 process, there is a mixed structure in the part core. The paper focuses on the IQ-3 method that provides a bainitic structure in the part core. A method for calculation of a required water flow rate for high-velocity IQ systems for providing the bainitic part core structure is discussed.
\end{abstract}

Keywords: direct convection, IQ-3 process, distortion, crack formation, ductility, strength, calculations.

\section{Introduction}

Before discovering of the intensive quenching (IQ) process by the author of this paper, it was a well-known fact in a heat treating practice that a correlation between a probability of part cracking and part cooling rate during quenching is represented by a parabolic curve: the higher the part cooling rate the greater the probability of part cracking and the greater the part distortion. The IQ process phenomenon proved that this is not always the case. Actually, the correlation between the probability of part cracking and the cooling rate is represented by a bell-shaped curve (Fig. 1). When the part cooling rate becomes extremely high, the probability of part cracking and part distortion drastically drop. This unusual behavior of part cracking and distortion is explained by a very high current surface compressive stresses developed during the IQ process. These surface compressive stresses remain in the part after the IQ process is completed. Residual surface compressive stresses work like a die keeping the part together, preventing part cracking and reducing part distortion. In addition to beneficial residual surface compressive stresses, both the part strength (due to a deeper hardened layer) and the part ductility (due to a better material microstructure) improve as a result of intensive quenching [1-8].

The (IQ) process is an interrupted quench method conducted in highly agitated water and then in the air. Two IQ processes are currently used in heat treating practice: an IQ-2 processes that is implemented in IQ water tanks for batch quenching of steel parts and an IQ-3 method that is usually used for single-part quenching in high-velocity IQ units. A detailed description of these IQ processes is presented in [6-8]. This paper considers only the IQ-3 process. The IQ-3 method is characterized by a very high water flow rates within the quench chamber. When quenching steel parts in high-velocity IQ units, the part surface temperature drops almost instantly to the water temperature. Both the film boiling process and the nucleate boiling process are eliminated under these conditions. A convection mode of heat transfer starts right away after the beginning of the quench. Therefore, the IQ-3 process is often called a direct convection quenching. Such intensive cooling decreases distortion of steel parts prevents crack formation, increases strength and ductility of materials.

The cooling rate $\mathrm{v}$ that provides heat transfer conditions required by the IQ-3 process is calculated by the following equation:

$$
\mathrm{v}=\frac{\mathrm{aKn}}{\mathrm{K}}\left(\mathrm{T}-\mathrm{T}_{\mathrm{m}}\right)
$$


where is $\mathrm{V}$ cooling rate in $\mathrm{m} / \mathrm{s}$; a is thermal diffusivity of steel in $\mathrm{m}^{2} / \mathrm{s} \mathrm{Kn}$ is dimensionless Kondratjev number; $\mathrm{K}$ is Kondratjev form factor in $\mathrm{m}^{2} ; \mathrm{T}_{\mathrm{m}}$ is quenchant temperature.

In this paper, the above IQ phenomena is discussed in details and an essential improvement of the IQ-3 process is proposed.

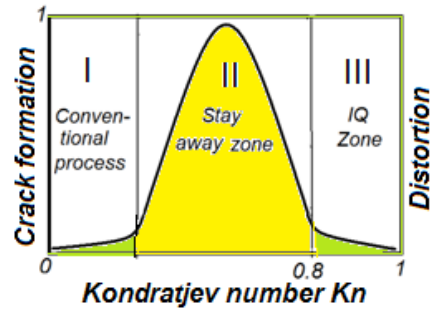

Fig. 1. Crack formation and distortion versus Kondratjev number Kn: I - conventional processes (quenching in oil, polymers of high concentration or vacuum gas quenching); II - stay away zone;

$$
\text { III - intensive quenching zone }
$$

\section{Phenomena taking place in zone III}

\section{1. Decreased distortion}

The first fundamental investigations of the effect of the accelerated cooling rate on the distortion of the bearing ring made of AISI 52100 steel, were performed in 1970-1980 and published in the book (Fig. 2) [1].
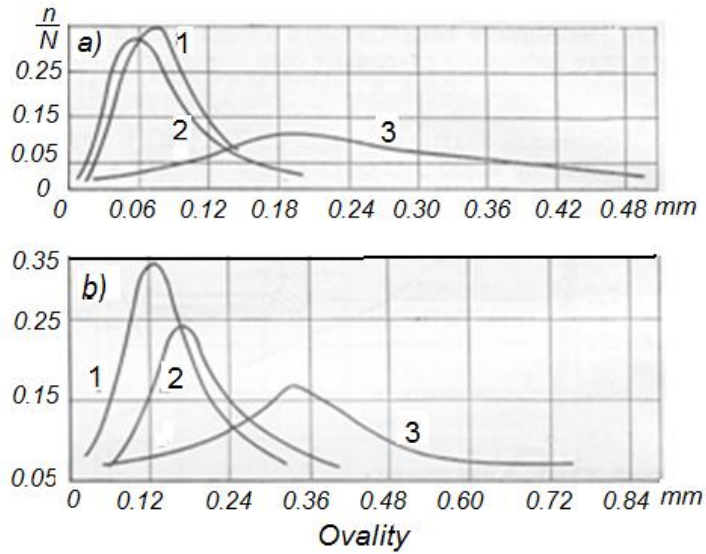

Fig. 2. Ovality of bearing rings $208 / 01$ (a) and $308 / 01$ (b) during quenching from $860{ }^{\circ} \mathrm{C}$ in various quenchants at $30-40{ }^{\circ} \mathrm{C}$ in: 1 - oil; 2 - an aqueous solution of $\mathrm{CaCl}_{2} ; 3$ - water $[1,6]$

As seen from Fig. 2, the ovality of bearing rings quenched in oil and in water salt solutions is almost the same (curves 1,2). When quenched in plain water, the bearing rings distortion is three times greater than that after quenching in oil (curve 3). During quenching in water, all bearing rings cracked. There were no cracks during quenching in oil and in water salt solutions $[1,6]$. During quenching in water, cracks were formed on boundaries of the local film boiling. The crack formation and big distortion are caused mainly by the local film boiling due to a non-uniform cooling, and, as a result, due to the formation of a non-uniform martensitic shell at the surface of the bearing rings. To be sure that the phenomenon described above is true, let's consider quenching in a high velocity system (Fig. 3).

Keyway shafts shown in Fig. 4, 5 were quenched in oils and in the high velocity IQ system (Fig. 3). Results of the keyway distortion measurements are presented in Table 1. As seen from Table 1, the IQ-3 process provides three times less distortion as compared to oil quenching. Obtained results proof the idea that high cooling rates is not a reason for the high part distortion when a uniform cooling is provided. 


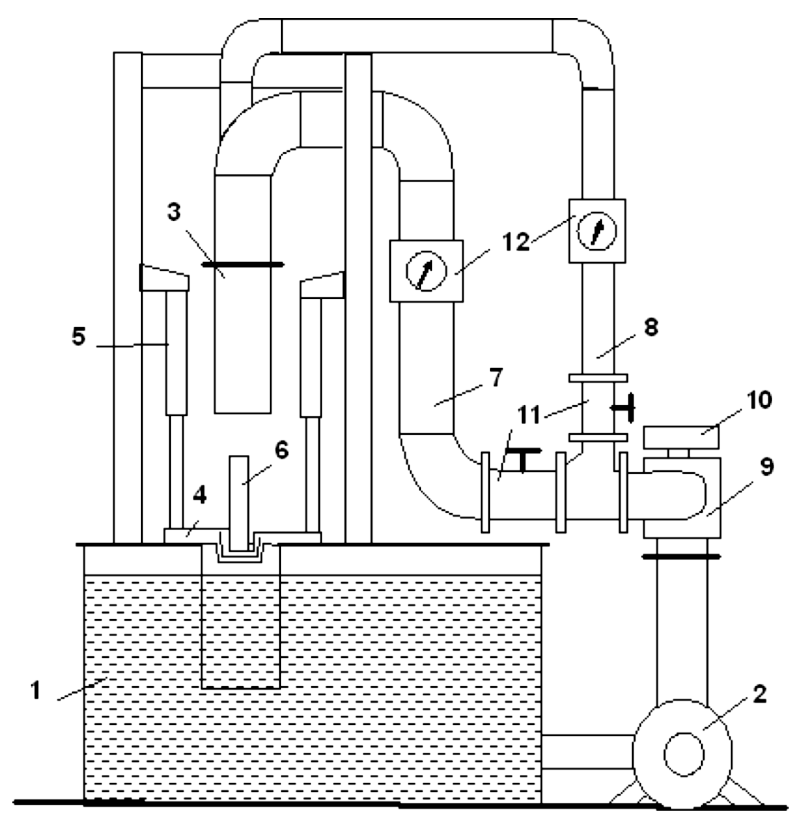

Fig. 3. High-velocity experimental IQ system sketch [6-9]: 1 - water tank; 2 - pump; 3 - stationary upper section of the vertical quench chamber; 4 - movable lower section (loading table) of the quench chamber; 5 - air cylinders; 6 - keyway shaft; 7, 8 - water lines; 9 - three-way valve; 10 - actuator; 11 - control valves; 12 - flow meters

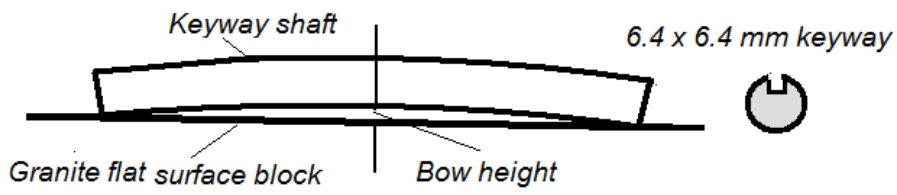

Fig. 4. Keyway shaft distortions [6]

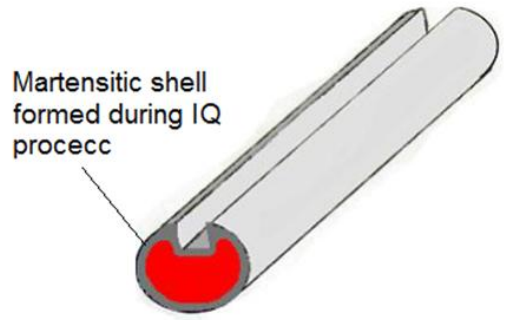

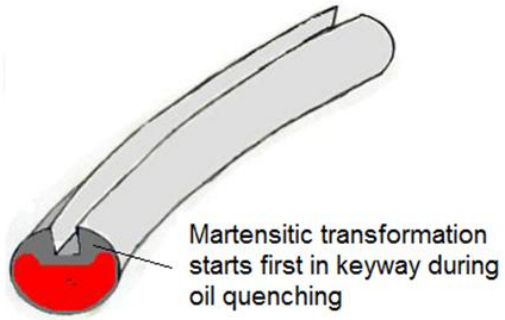

$b$

Fig. 5. Martensitic uniform shell formation in keyways during IQ process: $a$-providing minimum distortion due to uniform shell formation during IQ process; $b$ - resulting in essential distortion due to non-uniform shell formation during oil quenching (Table 1) [10]

Table 1

Keyway distortion measurements [6]

\begin{tabular}{ccc}
\hline Batch oil & Single oil & Single IQ \\
\hline $0.25-0.51 \mathrm{~mm}$ & $0.20-0.36 \mathrm{~mm}$ & $0.08-0.12 \mathrm{~mm}$
\end{tabular}

\section{2. High compressive residual stresses}

In zone III, high compressive residual stresses are formed in the surface layer of steel parts. Some results of the residual surface stresses measurements are presented in Table 2. 
Table 2

Residual compressive stresses at the surface of steel parts made of different steel grades and intensively hardened in high-velocity IQ unit [6]

\begin{tabular}{ccc}
\hline Part name & Steel AISI & Compressive residual stresses, MPa \\
\hline Bearing roller $76 \mathrm{~mm}$ in diameter & 52100 & -840 \\
Kingpin $46 \mathrm{~mm}$ in diameter & 4140 & -563 \\
Output shaft $41 \mathrm{~mm}$ in diameter & 1060 & -660 \\
Punch $38 \mathrm{~mm}$ in diameter & S5 & -750
\end{tabular}

\subsection{Superstrengthened material}

An additional strengthening (superstrengthening) of the material is observed when the part cooling rate at the beginning of the martensite transformation is high enough. Some results of the measurement are presented in Table 3 [1, 2].

Table 3

Additional strengthening of material when high cooling rate at martensite start temperature $[1,2]$

\begin{tabular}{cccccc}
\hline Quenchant & Cooling rate & $\mathbf{R}_{\mathbf{m}}, \mathbf{M P a}$ & $\mathbf{R}_{\mathbf{p} 0.2}, \mathbf{M P a}$ & $\mathbf{A}, \mathbf{\%}$ & $\mathbf{Z}, \mathbf{\%}$ \\
\hline Oil & 3 & 1460 & 1370 & 7.6 & 22 \\
Liquid nitrogen under vibration & 30 & 1610 & 1570 & 7.9 & 31
\end{tabular}

Note: U7A (0.65-0.74 C; $0.15-0.35 \mathrm{Si} ; 0.15-0.30 \mathrm{Mn}$ in wt \%)

As one can see from Table 3, ultimate strength of material increased for $10 \%$ along with the improvement of its ductility.

\section{Cooling time calculation method for IQ-3 processes}

To eliminate the film boiling and nucleate boiling processes completely, one should use equations (2) and (3),which allow determining heat transfer coefficients (HTCs) providing a direct convection mode of heat transfer. Then evaluated HTC should be taken into account when calculating the Nusselt number Nu. Knowing the Nusselt number and Prandtl number Pr, it is possible to determine the Reynolds number Re (see Eq. (4)) which includes a value of the flow velocity of liquid in the channel or in the quench fixture 3 (Fig. 3).

$$
\begin{gathered}
\operatorname{Bi}=\frac{2\left(\vartheta_{0}-\vartheta_{\mathrm{I}}\right)}{\vartheta_{\mathrm{I}}+\vartheta_{\mathrm{uh}}}, \\
\vartheta_{\mathrm{I}}=\frac{1}{\beta}\left[\frac{2 \lambda\left(\vartheta_{0}-\vartheta_{\mathrm{I}}\right)}{\mathrm{R}}\right]^{0.3}, \\
\operatorname{Re}=\left(\frac{\mathrm{Nu}}{0.03 \operatorname{Pr}^{0.43}}\right)^{1.25}, \\
\tau=\left[\frac{\mathrm{kBi}_{\mathrm{V}}}{2.095+3.687 \mathrm{Bi}_{\mathrm{V}}}+\ln \frac{\mathrm{T}_{0}-\mathrm{T}_{\mathrm{m}}}{\mathrm{T}-\mathrm{T}_{\mathrm{m}}}\right] \frac{\mathrm{K}}{\mathrm{aKn}}
\end{gathered}
$$

where $\mathrm{Bi}$ is Biot number; $\mathrm{Re}$ is Reynolds number; $\mathrm{Bi}_{\mathrm{V}}$ is generalized Biot number; $\mathrm{Kn}$ is Kondratjev number [11]; $\mathrm{K}$ is Kondratjev form factor [11]; $\mathrm{Nu}$ is Nusselt number; $\mathrm{Pr}$ is Prandtl number; $\vartheta_{0}=T_{0}-T_{s} ; T_{0}$ is initial temperature; $T_{s}$ is saturation temperature; $\vartheta_{I}=T_{I}-T_{s} ; T_{I}$ is surface temperature during initial boiling process; $\mathrm{T}_{\mathrm{m}}$ is liquid temperature; $\beta=3.46 ; \mathrm{R}$ is radius or thickness of plate; $\lambda$ is thermal conductivity of steel; a is thermal diffusivity of steel. 
Once the water flow velocity in channel is determined, one should calculate the cooling time for the steel part being quenched using Eq. (5), where the direct convection mode of heat transfer takes place from the very beginning of the cooling process. According to US Patent No.: US 6,364,974 B1, the core cooling interruption time of steel part corresponds to the moment when surface current compressive stresses achieve their maximal value [12-17]. Then the steel part is put for tempering. However, the part core temperature at the moment of the interruption can vary from $200{ }^{\circ} \mathrm{C}$ to $600{ }^{\circ} \mathrm{C}$ depending on the steel part configuration, type of steel and intensity of cooling. Furthermore, high compressive residual stresses can be formed at the surface even in the parts made of through hardened alloy steels if the intensity of quenching is high enough and $\mathrm{Kn} \rightarrow 1$. It means that compressive residual stresses at the part surface depends on the part core temperature in significantly. However, the material microstructure in the core differs fundamentally in this case. It means that the interruption cooling time should correspond to a fine bainitic microstructure or nano-structure at the steel part core. The fine bainitic and nano-bainitic structures provide a very high material strength and ductility in the steel part core. It is an idea that makes a difference in the method of cooling time calculations.

\section{Improvement of the IQ-3 processes}

To explain how one can improve the IQ-3 process, let's consider the following example. Assume that there is a cylindrical sample of $50 \mathrm{~mm}$ diameter and $300 \mathrm{~mm}$ long made of ASTM 4135 steel. It should be quenched intensively from $860^{\circ} \mathrm{C}$ by direct convection in a fixture of $56 \mathrm{~mm}$ diameter in water of $20^{\circ} \mathrm{C}$. Intensive quenching should be interrupted when the part core temperature approaches the bainitic area. It is a need to develop recipes for such technology.

Direct convection starts when Eq. (2) is fulfilled:

$$
\mathrm{Bi}=\frac{2\left(\vartheta_{0}-\vartheta_{\mathrm{I}}\right)}{\vartheta_{\mathrm{I}}+\vartheta_{\text {uh }}}=\frac{2 \times(760-20)}{20+80}=14.8
$$

or

$$
\begin{gathered}
\mathrm{Bi}_{\mathrm{V}}=0.346 \times 20=6.92 \approx 7 \\
\vartheta_{\mathrm{I}}=\frac{1}{\beta}\left[\frac{2 \lambda\left(\vartheta_{0}-\vartheta_{\mathrm{I}}\right)}{\mathrm{R}}\right]^{0.3}=\frac{1}{3.46}\left[\frac{2 \times 22\left(760-\vartheta_{\mathrm{I}}\right)}{0.025}\right]^{0.3}=19.8^{\circ} \mathrm{C} \approx 20^{\circ} \mathrm{C} .
\end{gathered}
$$

Knowing the Biot number $\mathrm{Bi}$ or the generalized Biot number $\mathrm{Bi}_{\mathrm{V}}$, one can calculate HTC, which for our condition is $17,812 \mathrm{~W} / \mathrm{m}^{2} \mathrm{~K}$. Using the determined HTC, we can determine the Nusselt number $\mathrm{Nu}$. The equivalent diameter for calculating the $\mathrm{Nu}$ and Reynolds numbers is $\mathrm{d}_{\text {eq }}=\mathrm{D}-\mathrm{d}=56 \mathrm{~mm}-50 \mathrm{~mm}=6 \mathrm{~mm}$ or $0.006 \mathrm{~m}$. It means that:

$$
\mathrm{Nu}=\frac{17812 \mathrm{~W} / \mathrm{m}^{2} \mathrm{~K}}{0.697 \mathrm{~W} / \mathrm{mK}} \times 0.006 \mathrm{~m}=153.3
$$

where $0.697 \mathrm{~W} / \mathrm{mK}$ is the thermal conductivity of water at $20^{\circ} \mathrm{C}$.

Substituting the Nusselt number into Eq. (4), we can determine the Reynolds number Re, which, for our case, is:

$$
\operatorname{Re}=\left(\frac{153.3}{0.03 \times 7.03^{0.43}}\right)^{1.25}=15146
$$

where 7.03 is Prandtl number for water at $20^{\circ} \mathrm{C}$.

The water flow velocity in the quench chamber (Fig. 3) can be calculated from the Reynolds number as

$$
\mathrm{v}=15146 \times \frac{1.006 \times 10^{-6} \mathrm{~m}^{2} / \mathrm{s}}{0.006 \mathrm{~m}}=2.54 \mathrm{~m} / \mathrm{s} \approx 3 \mathrm{~m} / \mathrm{s}
$$


It means that the water flow velocity in the quench chamber in the high velocity IQ system (Fig. 3) for the sample of $50 \mathrm{~mm}$ diameter should be higher than $3 \mathrm{~m} / \mathrm{s}$ to eliminate the nucleate boiling process and to provide the direct convection mode of heat transfer.

As a rule, the IQ-3 process in the heat treating practices performed as follows. After heating and intensive interrupted quenching in water flow (Fig. 3), hardened steel parts are cooled in the air and then transferred for tempering. It takes a long time during which the part core temperature drops below the bainitic transformation. Only in the bainitic zone, the material mechanical properties are rather high (especially the impact strength, Fig. 6 and Table 4).

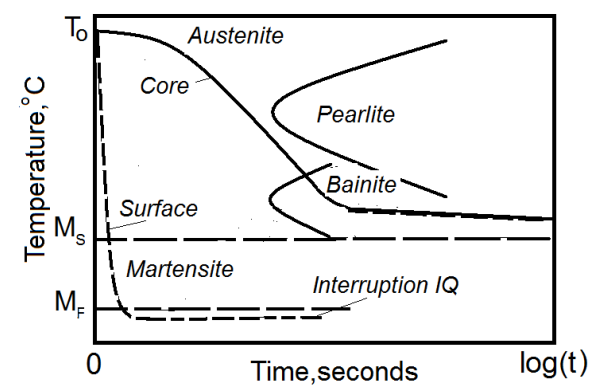

Fig. 6. Schematic of the corrected IQ-3 process which increases essentially impact strength of material in the steel part core

Table 4

Comparison of mechanical properties in the core of cylindrical samples made of ASTM 4135 steel, quenched in oil and in water salt solution, and tempered at $540{ }^{\circ} \mathrm{C}[18-20]$

\begin{tabular}{ccccccc}
\hline Quenchant & $\mathbf{R}_{\mathrm{m}}, \mathbf{M P a}$ & $\mathbf{R}_{\mathrm{p} 0.2}, \mathbf{M P a}$ & $\mathbf{A ~ ( \% )}$ & $\mathbf{Z}(\mathbf{\%})$ & $\mathbf{a}_{\mathbf{k}}\left(\mathbf{J} / \mathbf{s m}^{2}\right)$ & $\mathbf{H B}$ \\
\hline Oil & 960 & 775 & 14 & 53 & 54 & 285 \\
Water salt solution & 970 & 820 & 17 & 63 & 150 & 285
\end{tabular}

More information on bainitic transformations one can find in Ref [21].

\section{Discussion}

For the first time, the IQ-3 process was discovered and patented in Ukraine (UA Patent No 4448). Nobody could believe that an accelerated cooling decreases part distortion, increases material strength along with increasing the part ductility, creates high compressive residual stresses in the part surface layer, and eliminates completely a quench crack formation. The IQ process phenomena always sounds as a crazy idea, even today, and nobody desires to take responsibility to use widely such technology in the practice. In 1999 author received permission from the Ukrainian patenting office to patent the IQ-3 technology abroad. It was patented in USA. A first IQ quench tank, equipped with a $U$ - tube and high-efficiency propeller to provide a highly agitated water flow (with the velocity of up to $2 \mathrm{~m} / \mathrm{s}$ ) was built and installed at the Akron Steel Treating Company [6]. Bearing rings, made of AISI 52100 steel (which are sensitive to cracking in water) were tested. A possibility of eliminating of quench cracks by using intensive quenching was proved. The results of these experiments, the IQ-3 method and design of the high velocity systems are discussed in the ASM and Elsevier books [7, 8]. The improvement of the IQ-3 technology consists in the interruption of intensive quenching when the part core temperature is in bainitic zone. This zone is located between martensite start temperature and pearlitic transformations. Only painstaking experiments can answer the question what temperature is optimal in bainitic zone and how long the material should be tempered after the interruption of intensive quenching. A correlation between the martensite start temperature $\mathrm{M}_{\mathrm{S}}$ and the maretensite finish temperature $\mathrm{M}_{\mathrm{F}}$ and the carbon content in steel is provided in Table $\mathbf{5}$. 
Table 5

Martensite start and fnish temperature depending on percentage carbon in steel

\begin{tabular}{cccccccc}
\hline$\%$ C & $\mathbf{0 . 3}$ & $\mathbf{0 . 4}$ & $\mathbf{0 . 5}$ & $\mathbf{0 . 6}$ & $\mathbf{0 . 7}$ & $\mathbf{0 . 9}$ & $\mathbf{1 . 1}$ \\
\hline $\mathrm{M}_{\mathrm{S}},{ }^{\circ} \mathrm{C}$ & 380 & 360 & 320 & 290 & 275 & 235 & 180 \\
$\mathrm{M}_{\mathrm{F}},{ }^{\circ} \mathrm{C}$ & 200 & 100 & 20 & 0 & -50 & -80 & -100
\end{tabular}

The phenomena, discussed in this paper, have a great practical value, especially for increasing of the part service life after intensive quenching. Also, it should be mentioned that the IQ-3 process can decrease the carburization time for $25-40$ percent $[22,23]$.

\section{Conclusions}

1. The IQ-3 process eliminates the crack formation during quenching, decreases distortion of steel parts, increases the material strength and ductility, forms very high compressive residual stresses in the part surface layer, decreases the carburizing time as compared with oil quenching.

2. The IQ-3 process should be interrupted when the part core temperature approaches an optimal temperature in the bainitic zone, and after interrupting of the IQ process, the steel part should be immediately put for tempering at a temperature that provides a fine bainite or nano-bainite structure.

3. Quench fixtures used in high velocity IQ systems should be further improved to provide a more uniform and more intensive cooling at optimized energy expenses.

\section{Acknowledgements}

Author is grateful to Dr. M. A. Aronov, CEO of the IQ Technologies, Inc., Akron, USA, who edited the manuscript and designed and introduced to practice several production high velocities systems IQ systems for implementing IQ-3 processes.

\section{References}

[1] Kobasko, N. I. (1980). Steel Quenching in Liquid Media under Pressure. Kyiv: Naukova Dumka, 206.

[2] Kobasko, N. I.; Liscic, B., Tensi, H. M., Luty, W. (Eds.) (1992). Intensive Steel Quenching Methods.Theory and Technology of Quenching. Berlin: Springer-Verlag, New York, Tokyo, 367-389.

[3] Kobasko, M. I. (2002). Quenching Apparatus and Method for Hardening Steel Parts, Patent No.: US 6,364,974 B1.

[4] Kobasko, N. I.; Liscic, B., Tensi, H. M., Canale, L. C. F., Totten, G. E. (Eds.) (2010). Intensive Steel Quenching Methods, Quenching Theory and Technology, Second Edition. CRC Press, Boca Raton, London, New York, 509-567.

[5] Kobasko, N. I.; Wang, Q. J., Chung, Y.-W. (Eds.) (2013). Tribological Properties of Intensively Quenched Materials.Encyclopedia of Tribology. Springer, 3811-3816. doi: 10.1007/978-0-387-92897-5_1023

[6] Kobasko, N. I., Aronov, M. A., Powell, J. A., Totten, G. E. (2010). Intensive Quenching Systems: Engineering and Design. ASTM International, West Conshohocken, USA, 234. doi: 10.1520/mnl64-eb

[7] Aronov, M. A., Kobasko, N. I., Powell, J. A., Totten, G. E. (2013). Intensive Quenching of Steel Parts, ASM Handbook, Volume 4A, Steel Heat Treating Fundamentals and Processes, ASM International, Materials Park, 198-212.

[8] Kobasko, N. I., Aronov, M. A. (2014). 12.07 - Intensive Quenching, Reference Module in Materials Science and Materials Engineering, Volume 12: Thermal Engineering of Steel Alloy Systems, 253-269. doi: 10.1016/B978-0-08-096532-1.01208-5

[9] Kobasko, N. I., Aronov, M. A., Powell, J. A., Ferguson, B. L. (2014). Verification of Presence of Direct Convection Mode of Heat Transfer During Intensive Quenching in High Velocity IQ System. "Recent Advances in Intelligent Control, Modeling and Simulation", Hitoshi Kijima, Ed., WSEAS Press, Cambridge, MA, 165-170.

[10] Powell, J. A. (2013). Basics of IQ Process, Presentation at Intensive Quenching Workshop, Cleveland, Ohio, USA.

[11] Kondratjev, G. M. (1957). Teplovye Izmereniya (Thermal Measurements), Mashgiz, Moscow. 
[12] Rath, J., Luebben, Th., Hunkel, M., Hoffman, F., Zoch, H.-W. (2009). Basic researches aboutthe generation of compressive stresses by high speed quenching, HTM J. Heat Treatm.Mat., 64 (6), 338-350.

[13] Rath, J., Luebben, Th., Hoffman, F., Zoch, H.-W. (2010). Generation of compressive residualstresses by high speed water quenching. International Heat Treatment and Surface Engineering, 4 (4), 156159. doi: $10.1179 / 174951410 \times 12851626812970$

[14] Kobasko, N. I., Aronov, M. A., Ichitani, K., Hasegawa, M., Noguchi, K. (2012). High Compressive Residual Stresses in Through Hardened Steel Parts as a Function of Biot Number. In a Book "Recent Advances in Fluid Mechanics, Heat and Mass Transfer and Biology". WSEAS Press, Cambridge, MA, USA, 35-40.

[15] Kobasko, N. I. (1995). Basics of Intensive Quenching. Advanced Materials\& Processes/Heat Treating Progress, Part I, 148 (3), 42W-42Y.

[16] Kobasko, N. I., Morhuniuk, W. S., Ushakov, B. K. (2004). Design of Steel - Intensive Quench Processes. Handbook of Metallurgical Process Design. New York, Basel, 733-764.

[17] Kobasko, N. I., Morhuniuk, W. S. (1985). Numerical Study of Phase Changes, Current and Residual Stresses at Quenching Parts of ComplexConfiguration, Proceedings of the 4th International Congressof Heat Treatment Materials, 1, 465-486.

[18] Mukhina, M. P., Kobasko, N. I., Gordeeva, L. V. (1989). Hardening of structural steels in cooling media based on chlorides. Metal Science and Heat Treatment, 31 (9), 677-682. doi: 10.1007/bf00717487

[19] Kobasko, N. (2005). Steel Superstrengthening Phenomenon. Journal of ASTM International, 2 (1), doi: $10.1520 /$ jai12824

[20] Kobasko, N. I. (2005). Steel superstrengthening phenomenon, part I. International Journal of Materials and Product Technology, 24 (1/2/3/4), 361. doi: 10.1504/ijmpt.2005.007961

[21] Bhadeshia, H. K. D. H. (2015). Bainite in Steels: Theory and Practice (3rd edition), Money Publishing, 616.

[22] Kobasko, N. I., Aronov, M. A., Powell, J. A., Ghorpade, P. (2005). Application of Intensive Quenching Processes for CarburizedParts, Proceedings of the 25th Heat Treating Conference, Puna, India (CD-ROM).

[23] Kobasko, N. I., Aronov, M. A., Powell, J. A., Ghorpade, P. (2007). Demonstrations of Intensive Quenching Methods for Steel Parts, Proceedings of the 27th Heat Treating Conference, Detroit, USA. 